\title{
VALORES E CRENÇAS PARENTAIS: REFLEXÕES TEÓRICAS ${ }^{+}$
}

\author{
VALUES AND BELIEVES PARENTAL: THEORETICAL CONSIDERATIONS
}

Ana P. R. Kobarg*

Vírginia A. R. Sachetti*

Mauro L. Vieira ${ }^{* * *}$

Kobarg APR, Sachetti VAR, Vieira ML. Valores e crenças parentais: reflexões teóricas. Rev Bras Crescimento Desenvolv Hum. 2006; 16(2):96-102.

Resumo: O contexto cultural permite o acúmulo de informações dentro de um grupo que se reflete em crenças e práticas. Compreender a relação entre a natureza humana e cultura é uma questão complexa e necessária para a compreensão do comportamento. Ampliar pesquisas enfocando a complexa relação entre o biológico e o social promove um melhor entendimento sobre o desenvolvimento, o que significa que estudar crenças e práticas permite entender melhor a relação entre o homem e a cultura e, conseqüentemente, compreender melhor o comportamento humano. A importância do estudo de crenças parentais para a compreensão do desenvolvimento humano mostra que os sistemas de crenças parentais têm emergido como um campo de estudo relevante para a compreensão do desenvolvimento por estar diretamente vinculado ao estilo de cuidado dispensado à criança.

Palavras-chave: Cuidado parental. Valores. Crenças. Cultura.

\section{INTRODUÇÃO}

O comportamento parental tem sido de interesse de pesquisadore ${ }^{1-4}$; parte dessa motivação se dá pela existência de diferentes teorias que procuram investigar a natureza das situações vividas durante a infância e os possíveis efeitos que possam ter sobre as esferas cognitiva, emocional e social da criança. O comportamento parental corresponde, dessa forma, à relação que os cuidadores estabelecem com a criança, desde sua concepção até a vida adulta.

Na psicologia, há décadas busca-se es- tabelecer o princípio de que a estruturação do cuidado à infância, as práticas adotadas e as crenças que presidem essas práticas variam ao longo da história humana e são moldados pela cultura. Desse modo, diferenciam-se entre grupos culturais humanos, constituídos por pessoas que compartilham um conjunto de artefatos, práticas e sistemas de crenças ${ }^{5}$. Ao mesmo tempo, subsiste a pergunta central da psicologia do desenvolvimento: responder como os organismos se desenvolvem, o que implica explicar as continuidades (ou descontinuidades) que ligam as diversas etapas do caminho que os organis-

O trabalho faz parte do NEPeDI_ Núcleo de Estudos e Pesquisas em Desenvolvimento Infantil - Departamento de Psicologia da Universidade Federal de Santa Catarina (UFSC).

* Pedagoga e Historiadora, mestranda do Programa de Pós-Graduação do curso de Psicologia da UFSC. Rua: Uruguai, 122; apto-203. Centro, Itajaí SC. E-mail: paulariko@hotmail.com

** Psicóloga, professora da Faculdade Metropolitana de Guaramirim e doutoranda em Psicologia na Universidade Federal de Santa Catarina.

*** Psicólogo, Doutor em Psicologia pela Universidade de São Paulo e Pós-Doutorado pela Dalhousie University, Canadá. Professor Adjunto do Departamento de Psicologia da Universidade Federal de Santa Catarina. Endereço para correspondência: Departamento de Psicologia, Universidade Federal de Santa Catarina. Campus Universitário Trindade. CEP: 88040-900. Florianópolis-SC. E-mail: vieira@cfh.ufsc.br 
mos percorrem ao longo de suas vidas. Desse modo, os diferentes modelos de desenvolvimento têm a tarefa de descrever e explicar as transações entre organismos e ambientes e como elas estão relacionadas às mudanças que chamamos de ciclo de vida.

"Todo mundo tem uma teoria da natureza humana"6. O autor afirma que essas teorias, implícitas em todas as decisões que as pessoas tomam ao longo da vida, direcionam, entre outras coisas, a maneira de criar os filhos, o controle do comportamento, os objetivos e valores. Evidências relatadas por Yamamoto e Lopes $^{7}$ sugerem que a mente humana é produto da história evolutiva da espécie para desenvolver características que são identificadas como especialmente humanas: o homem é um ser social, cultural, que se comunica e transmite padrões específicos de sua comunidade. Essas características, presentes em todos os contextos, formam o que é conhecido como natureza humana, biologicamente universal, que define o homem como espécie.

Valores, crenças, idéias e práticas parentais recentemente têm sido objeto de estudo de autores interessados nos vários aspectos do desenvolvimento humano $8,9,10,11,3,12,13,2,14,15$. Mesmo assim, Melchiori e Biasoli-Alves ${ }^{16}$ apontam que ainda há escassez de estudos na área, e argumentam que isso deve servir de incentivo e desafio, ao invés de limitação, aos pesquisadores interessados em investigar valores, idéias e crenças parentais.

Há ainda uma outra dificuldade no estudo de crenças: a definição dos termos não tem sido uma tarefa simples. Moura e cols. ${ }^{14}$ afirmam que é possível observar na literatura que os autores empregam diferentes estratégias para estudar crenças, valores, idéias e atitudes parentais sem haver preocupação com uma definição mais rigorosa e precisa dos conceitos. Melchiori e Biasoli-Alves ${ }^{16}$ também apontam que a utilização desses termos é controversa. Assim, é possível encontrar diferentes autores, ainda que pertencentes à mesma orientação teórica, utilizando termos diversos para designar o mesmo objeto de estudo. Por exemplo, Sigel e cols. ${ }^{15}$ propõem o uso de um termo mais geral e amplo, que denominam cognição paren$\mathrm{tal}^{++}$quando se referem ao assunto enquanto Harkness e Super ${ }^{3}$ utilizam o termo etnoteorias e sistema cultural de crenças com a mesma definição.

A despeito dessas dificuldades, há concordâncias. Em primeiro lugar, os autores que estudam o assunto assumem que o comportamento dos pais não ocorre ao acaso, mas é fundamentado em idéias e crenças organizadas, subjacentes ao comportamento diário, sobre a forma de lidar com os filhos. Concordam também que valores, idéias, crenças e o comportamento não podem ser compreendidos de forma isolada, mas somente como aspectos inseparáveis. Além disso, apontam que valores, idéias, crenças estão extremamente ligados à cultura e ao contexto de desenvolvimento da criança. A transmissão de cultura de uma geração a outra pode ser considerada uma questão específica no desenvolvimento humano ${ }^{17-20}$, em primeiro lugar, no sentido de hábitos e costumes diários que são transmitidos e compartilhados por um grupo de uma geração para outra e, em segundo lugar, no sentido de possuir um modo de vida cultural altamente especializado.

\section{Crenças e comportamento humano}

A relação existente entre crenças e comportamento é objeto de estudo antigo da antropologia e recente da psicologia ${ }^{11,15}$. Para a antropologia tradicional, a cultura varia de um local para outro e inclui um conjunto de valores e crenças compartilhados. A psicologia redefine

\footnotetext{
${ }^{++}$No original, “parent cognition” (p. xiii).
} 
esse conceito ao acrescentar uma dimensão comportamental: as práticas ${ }^{17}$. Atualmente já é possível afirmar que "um dos aspectos culturais mais relevantes para a compreensão do desenvolvimento humano refere-se aos valores, crenças e práticas predominantes em uma determinada cultura"21. E isso é especialmente evidenciado nos estudos, como o de Biasoli-Alves ${ }^{8}$, que apresentam dados de pesquisa sustentando que os valores e crenças compartilhados pelos pais sobre o desenvolvimento de seus filhos influenciam o comportamento e as práticas parentais, além de afetar as interações que são estabelecidas com as crianças. Keller ${ }^{19}$ e Mou$\mathrm{ra}^{14}$ assumem que as crenças dos cuidadores afetam as práticas do cuidado destinado à criança, bem como a interação entre crenças, práticas e ambiente.

A compreensão dos pais sobre a natureza da criança, a estrutura do desenvolvimento e o significado de um comportamento é, não somente compartilhada pelos membros de um grupo cultural, mas também reconstruída na mente dos membros de um grupo, ou seja, a compreensão é formada a partir da interpretação que os pais dão à realidade na qual estão inseri$\operatorname{dos}^{22,3,2}$. Essas compreensões são desenvolvidas em um contexto específico, um determinado local e em um determinado tempo, ou seja, são social, cultural e historicamente determinadas. Como as compreensões culturais que os pais apresentam são organizadas em categorias mais amplas de crenças, são denominadas sistemas culturais de crenças parentais ou etnoteorias parentais e são traduzidas em termos de ações relativas à criação de filhos que exercem influência na saúde e desenvolvimento das crianças.

Lighfoot e Valsiner $^{1}$ e Suizzo ${ }^{23}$ também utilizam o nome sistema cultural de crenças e apontam a cultura como um componente essencial no contexto dentro do qual os pais cuidam das crianças, modelando o comportamento de ambos. Afirmam ainda que não é possível separar contexto e sistema cultural de crenças porque este permeia todas as experiências da vida diária dos pais e do grupo no qual estão inseridos. Assim, o processo de construção do sistema de crenças supõe um indivíduo ativo, inserido em uma cultura que, ao mesmo tempo, compartilha as crenças do grupo e as reconstrói por meio de seus mecanismos psicológicos, elaborando, assim, um sistema de crenças subjetivo e único.

\section{Etnoteoriais ou sistemas de crenças parentais}

Os sistemas de crenças parentais ou etnoteorias, que podem ser definidas como conjuntos organizados de idéias que estão implícitos nas atividades da vida diária e nos julgamentos, escolhas e decisões que os pais tomam, funcionando como modelos ou roteiros para ações. As etnoteorias formam um quadro de referência interno (são pouco aparentes porque estão na mente dos pais) que sustenta o comportamento cotidiano dos pais e apresentam uma dimensão universal, mas são construídas dentro de uma determinada cultura $^{11,3}$. Keller e cols. ${ }^{13}$ relatam resultados de pesquisas sustentando essa argumentação ao demonstrar que idéias, crenças e etnoteorias parentais são recursos que pais utilizam para formar conceitos sobre desenvolvimento, para auto-avaliação da competência parental, para atribuição de sucesso ou fracasso ou para o estabelecimento de metas para si, para a criança e para a família.

Assim, a organização do cuidado que o adulto destina à criança é explicada por meio das etnoteorias parentais, definidas como entendimentos compartilhados que circunscrevem experiências e fornecem interpretações, inferências e objetivos para as ações ${ }^{22,11,3}$. São mais do que simplesmente crenças que permeiam idéias, mas incorporam também um conjunto estruturado de valores que direciona e organiza 
a vida da criança e da família. Esse pressuposto implica uma função adaptativa das etnoteorias: são estruturas sobre as quais são desenvolvidas competências em um determinado ambiente. Os mesmos autores, como também Suizzo ${ }^{23}$, relatam que as etnoteorias têm base cultural (são modelos ou sínteses de uma cultura específica) e têm sido investigadas como indicadoras de diferenças entre contextos. Como são específicas para o contexto, não somente em conteúdo, mas também em estilos de expressão ${ }^{12}$, têm sido objeto de investigação em estudos transculturais.

Ainda que as etnoteorias possam ser descritas como modelos compartilhados por membros de uma determinada comunidade, isso não significa afirmar que as idéias sejam deliberadas ou explícitas ${ }^{12}$. São padrões historicamente construídos e presentes nas práticas disponíveis aos membros de uma comunidade, que dão sentido ao ambiente. Seja qual for o modelo adotado para estudar o desenvolvimento, é preciso considerar a noção de etnoteorias parentais como um dos sistemas da dinâmica do contexto de desenvolvimento da criança e énecessário pensar em aspectos de ação (práticas) e representação (valores, crenças, atitudes e cognições) como inseparáveis ${ }^{14,15}$.

Dessen $^{21}$ e também Lima ${ }^{24}$ fazem uma diferenciação extremamente necessária para esclarecer alguns conceitos que servem de base para explicitar as definições aqui empregadas. Apontam que os valores são concepções sobre o que é pessoal ou socialmente desejável (envolve a explicitação de preferências), são indicadores de objetivos e metas que pessoas traçam e orientam a ação e as escolhas. Pereira e Camino ${ }^{25}$ também definem valores como organizações duradouras de crenças que as pessoas possuem, socialmente construídas e compartilhadas, que servem como critérios para orientar ações e julgamento. Crenças são definidas como um conjunto de informações que as pessoas possuem sobre um determinado obje- to, servindo de suporte para tomadas de posição diante de uma situação e representam as idéias sobre como favorecer o alcance aos objetivos. Então, é também possível afirmar que as crenças funcionam como fatores intermediários (mediadores) na relação existente entre valores e comportamentos ou práticas parentais. Assim, a definição adotada nesse trabalho descreve crenças nesse mesmo sentido, ou seja, como etnoteorias ${ }^{22,11,3,19,12}$, descrevendo valores como implícitos nas metas e objetivos ${ }^{26,14} \mathrm{e}$ práticas como ações ou estratégias.

\section{A importância de estudar valores, crenças e práticas parentais}

Como as etnoteorias parentais formam um conjunto organizado de idéias dos pais sobre a compreensão da criança, também funcionam como motivação para tomar decisões e modelar comportamentos ${ }^{13}$. Exatamente por isso, estão implícitas na vida diária que os pais têm com os filhos, resultam da história pessoal de interação e da cultura acumulada no grupo social de referência e são expressas nos diferentes grupos que os pais selecionam e organizam para a criança.

Lordelo ${ }^{27}$ infere que a espécie humana é caracterizada pelo alto investimento parental (definido normalmente em termos quantitativos: maior/menor cuidado físico/psicológico destinado à prole) que precisam ser investigados. Saraswathi ${ }^{28}$ acrescenta ainda duas novas respostas. O estudo transcultural de valores, crenças e práticas parentais e o impacto que têm sobre o desenvolvimento da criança produziram até hoje dados para compreender práticas universais e culturalmente diferenciadas. Além disso, o estudo das etnoteorias parentais proporciona avanços na compreensão das relações mútuas que são estabelecidas entre a cultura e o indivíduo. Mas é Goodnow ${ }^{10}$ quem resume a questão empregando quatro argumentos: (a) estudar as idéias dos pais permite compreender 
aspectos da cognição dos adultos e a influência da cultura no desenvolvimento da identidade pessoal; (b) são uma forma de entender as ações dos pais; (c) as idéias dos pais constituem um dos aspectos do contexto de desenvolvimento da criança; e (d) compreender as idéias presentes em mais de uma geração possibilita acessar o processo de transmissão e transformação cultural. Assim, o estudo das etnoteorias incorpora descobertas de outras áreas, a exemplo do que ocorre no estudo de práticas parentais que exige o estudo da cultura dado uma refletir as transformações da outra.

Keller e cols. ${ }^{29}$ concordam que as práticas de cuidado à criança têm um impacto direto na formação da personalidade; assim, procuram identificar os mecanismos por meio dos quais essas diferenças são criadas, relacionando-as às propensões biológicas da espécie, às influências inter e intrageracionais, ajustadas pelas pressões de variáveis ecológicas, expressas no investimento parental.

Para entender os processos que caracterizam o desenvolvimento dinâmico dos indivíduos, bem como suas comunidades culturais em processo de mudança, é necessário identificar regularidades que descrevem as variações entre comunidades, bem como os pontos comuns na espécie humana. Pesquisas dessa amplitude fornecem informações e conhecimento científico que podem ser usados em benefício das famílias brasileiras, em projetos de promoção ou prevenção ligados à saúde, educação e área social.

Assim, investigar as crenças e práticas de cuidados maternos, bem como o investimento nestas relações, é de suma importância para avançar na produção de conhecimento sobre o desenvolvimento infantil.

\section{CONSIDERAÇÕES FINAIS}

A escassez de estudos a respeito das crenças parentais, ao invés de ser considerada limitadora, deveria ser vista como um grande desafio. Outro tema a ser investigado é se a diferença no comportamento das crianças é o resultado ou a causa das expectativas a respeito de seu desenvolvimento. As expectativas precoces dos adultos tendem a pressionar as crianças em direção à emissão precoce de alguns comportamentos, uma vez que há mais estimulação e atenção, reforçando a idéia da influência recíproca e bidirecional entre pais e filhos.

Perspectivas contemporâneas no âmbito da psicologia do desenvolvimento têm enfatizado o papel de fatores históricos, culturais e sociais sobre o desenvolvimento humano, sem minimizar a interação destes com fatores biológicos, incluindo aqui a bagagem genética individual e da espécie. Dentro dessa perspectiva, Harkness e Super ${ }^{3}$ têm discutido a relevância dos fatores históricos, culturais e sociais, explicitados no modelo ecológico de nichos de desenvolvimento. Esse modelo propõe que o desenvolvimento infantil processa-se em um nicho cujo eixo central é a casa (não importando a forma que esta assuma) da família (os cuidadores da criança). Esse nicho é concebido como um sistema composto por três subsistemas que se relacionam dinamicamente: o ambiente físico e social onde a criança vive (ex., tipo de moradia, tipo de organização social da família); os costumes estabelecidos cultural e historicamente, relacionados aos cuidados e à criação das crianças (ex., a noção de infância, e do que é apropriado para crianças, a relação entre as gerações, às formas de cuidados básicos e de educar crianças); a psicologia dos que cuidam das crianças (ex., crenças e expectativas de mães em relação a seus filhos).

Durante a fase adulta, indivíduos criam contextos de socialização para seus filhos, que são parte da sua própria história biográfica e de sua eco-cultura presente ${ }^{30}$. Assim, durante a infância, as crianças vão adquirindo modelos específicos para estabelecer relação entre contextos. 
As variações nas expectativas com relação às crianças passam a fazer sentido uma vez que tenhamos levado em conta diferentes circunstâncias e tradições ${ }^{12}$. Elas fazem sentido no contexto das diferenças do que está envolvido, por exemplo: na preparação de “uma refeição” ou ao “tomar conta” de um bebê; em quais as fontes de apoio e de perigos que são mais comuns; em quem mais está próximo; em qual é o papel dos adultos naquele lugar e de que forma eles vivem; em quais as instruções que as pessoas utilizam para organizar suas vidas; e nos objetivos da comunidade com relação ao desenvolvimento até o funcionamento adulto nessas instituições e práticas culturais.

Seja em uma tarefa cotidiana, seja na participação em um teste de laboratório, o desempenho das pessoas depende muito das circunstâncias que fazem parte da rotina em sua comunidade e das práticas culturais às quais elas estão acostumadas.

\begin{abstract}
The cultural context allows the gathering of information inside a group, and this is reflected on beliefs and practices. To understand the relationship between human nature and culture is a complex and necessary task for the comprehension of behavior. The conduction of more research studies focusing on the complex relationship between the social and the biological promotes a better understanding of development, which means that the study of beliefs and practices allows us to deepen our understanding of the relationship between men and culture and, consequently, to better understand human behavior. Thus, the study of parental beliefs is important to the comprehension of human development because it is directly linked with the style of child care.
\end{abstract}

Key-words: Parental care. Values. Beliefs. Culture.

\section{REFERENCIAS}

1. Lightfoot C, Valsiner J. Parental belief systems under the influence: social guidance of the construction of personal cultures. In: Sigel JE, McGillicuddy AV, Goodnow JJ, editors. Parental belief systems: the psychological consequenxes for children. $2^{\text {nd }}$ ed. Hillsdale (NJ): LEA; 1992. p. 393-414.

2. Lordelo ER, Fonseca AL, Araújo MLVB.

Responsividade do ambiente de desenvolvimento: crenças e práticas como sistema cultural de criação de filhos. Psicol Reflex Crít. 2000;13(1):73-80.

3. Harkness S, Super CM. Introduction. In: Harkness S, Super CM, editors. Parents' cultural belief systems: their origins, expressions and consequences. $2^{\text {nd }}$ ed. New York (NY): Guilford Press; 1996. p. 1-23.

4. Keller H, Papaligoura Z, Kuensemuller P, Völker S, Papaeliou C, Lohaus A, et al. Concepts of mother-infant interaction in Greece and Germany. J Cross Cult Psychol. 2003;34(6):677-89.

5. Rogoff B. A natureza cultural do desenvolvimento humano. Porto Alegre:
Artmed; 2005.

6. Pinker S. Tabula rasa: a negação contemporânea da natureza humana. São Paulo: Companhia das Letras; 2004.

7. Yamamoto ME, Lopes FA. Dize-me o que falas e eu te direi o que comes: aquisição da linguagem e composição de dieta em crianças. In: Moura MLS, organizador. O bebê do século XXI e a psicologia do desenvolvimento. São Paulo: Casa do Psicólogo; 2004. p. 205-27.

8. Biasoli-Alves ZMM. Continuidades e rupturas no papel da mulher brasileira no século XX. Psicol Teor Pesqui. 2000;16(3):233-9.

9. Bornstein MH. Child and family research in cross-cultural perspective. Int Soc Study Behav Dev Newsl. 2004;(45):17-20.

10. Goodnow J. From household pratices to parents' ideas about work and interpersonal relationships. In: Harkness S, Super CM, editors. Parents' cultural belief systems: their origins, expressions and consequences. $2^{\text {nd }}$ ed. New York (NY): Guilford Press; 1996. p. 313-44.

11. Harkness S, Super CM. Parental ethnotheories in action. In: Sigel IE, McGillicuddy-DeLisa AV, Goodnow J, editors. Parental belief systems: the psychological consequences for children. $2^{\text {nd }}$ 
ed. Hillsdale (NJ): LEA; 1992. p. 372-91.

12. Keller H, Hentschel E, Yovsi RD, Lamm B, Abels M, Haas V. The psycho-linguistic embodiment of parental ethnotheories: a new avenue to understanding cultural processes in parental reasoning. Cult Psychol. 2004;10(3):293-330.

13. Keller H, Lohaus A, Völker S, Elben C, Ball J. Warmth and contingency and their relationship to maternal attitudes toward parenting. J Genet Psychol. 2003;164(3):275-92.

14. Moura MLS, Ribas Júnior RC, Piccinini CA, Bastos ACS, Magalhães CMC, Vieira ML, et al. Conhecimento sobre desenvolvimento infantil em mães primíparas em diferentes centros urbanos do Brasil. Estud Psicol (Natal). 2004;9(3):421-9.

15. Sigel IE, McGillicuddy-DeLisi AV, Goodnow J. Introduction to the second edition. In: Sigel IE, McGillicuddy-DeLisi AV, Goodnow J, editors. Parental belief systems: the psychological consequences for children. $2^{\text {nd }}$ ed. Hillsdale (NJ): Erlbaum; 1992. p. xviii-xx.

16. Melchiori LE, Biasoli-Alves ZMM. Crenças de educadores de creche sobre temperamento e desenvolvimento de bebês. Psicol Teor Pesqui. 2001;17(3):285-92.

17. Baum WM. Compreender o behaviorismo: ciência, comportamento e cultura. Porto Alegre: Artmed; 1999.

18. Bussab VSR, Ribeiro FL. Biologicamente cultural. In: Souza L, Freitas MFQ, Rodrigues MMP, organizadores. Psicologia: reflexões (im)pertinentes. São Paulo: Casa do Psicólogo; 1998. p. 175-93.

19. Keller H. Development as the interface between biology and culture: a conceptualization of early ontogenetic experiences. In: Keller $\mathrm{H}$, Poortinga YH, Schölmerich A, editors. Between culture and biology: perspectives on ontogenetic development. Cambridge (UK): Cambridge Press University; 2002. p. 215-35.
20. Kreppner K. The child and the family: interdependence in development pathways. Psicol Teor Pesqui. 2000;16(1):11-22.

21. Dessen MA. Construindo uma ciência do desenvolvimento humano: passado, presente e futuro. In: Dessen MA, Costa Jr AL, organizadores. A ciência do desenvolvimento humano: tendências atuais e perspectivas futuras. Porto Alegre: Artmed; 2005. p. 264-78.

22. Harkness S, Super CM, Axia V, Eliasz A, Palacios J, Welles-Nyström B. Cultural pathways to sucessful parenting. Int Soc Study Behav Dev Newsl. 2001;(38):9-13.

23. Suizzo MA. French parents' cultural models and childrearing beliefs. Int J Behav Dev. 2002;26(4):292-307.

24. Lima MLP. Atitudes. In: Vala J, Monteiro MB, organizadores. Psicologia social. $2^{\mathrm{a}}$ ed. Lisboa: Fundação Calouste Gulbenkian; 1996.

25. Pereira C, Camino L. Um estudo sobre a integração dos níveis de análise dos sistemas de valores. Psicol Reflex Crít. 2005;1(1):16-25.

26. Miller AM, Harwood RL. Long-term socialization goals and the construction of infants' social networks among middle class Anglo and Puerto Rico mothers. Int J Behav Dev. 2001;25(5):450-7.

27. Lordelo ER. Interação social e responsividade em ambientes doméstico e de creche: cultura e desenvolvimento. Estud Psicol (Natal). 2002;7(2):343-50.

28. Saraswathi TS. Culture and parenting: beyond description of alternative beliefs and practices. Int Soc Study Behav Dev Newsl. 2001;(38):14-5.

29. Keller H, Poortinga YH, Schölmerich A. Between culture and biology: perspectives on ontogenetic development. Cambridge (UK): Cambridge University Press; 2002.

30. Keller H, Greenfield PM. History and future of development in cross-cultural psychology. J Cross Cult Psychol. 2000;31(1):52-62.

Recebido em 28/06/2006 Aprovado em 19/06/2006 